time in the low DAS categories. This supports that remission should be the primary T2T goal in in RA.

Disclosure of Interest: None declared

DOI: 10.1136/annrheumdis-2018-eular.3890

\section{FRI0016 NO RELATIONSHIPS BETWEEN ACPA AND PERIODONTITIS IN EARLY RHEUMATOID ARTHRITIS}

F. Mechid $^{1}$, C. Zehraoui ${ }^{1}$, M. Meddad ${ }^{2}$, S. Salah ${ }^{3}$, M. Benidir ${ }^{3}$, S. Merad ${ }^{4}$, N. Saidi ${ }^{1}$, O. Cheikh ${ }^{1}$, N. blidi ${ }^{1}$, C. Dahou ${ }^{1}$. ${ }^{1}$ Rheumatology, Mohamed Lamine Debaghine hospital; ${ }^{2}$ Periodontology, Mustapha Bacha Hospital; ${ }^{3}$ Immunology; ${ }^{4}$ Bacteriology, Dely brahim, institut Pasteur, Algiers, Algeria

Background: Proteins citrullination contributes to generate anticitrullinated peptide antibodies (ACPA) in rheumatoid arthritis (RA). Porphyromonas gingivalis $(\mathrm{Pg})$ is one of main germs incriminated in the development of periodontitis (PD), it has an enzyme called peptidyl arginine deiminase which is able to citrullinate the host proteins

Objectives: The aim of this study was to seek for a possible association between ACPA and periodontitis

Methods: We conducted a case-control study of 69 patients with early rheumatoid arthritis ( $\leq 2$ years), naive of biotherapy and 138 age-and sex matched healthy controls. Smokers, diabetics, and subjects who received dental care and those who used antibiotics in the previous 6 months were not included. Demographic data and ACPA were determined. A periodontal examination was performed to all participants. Subgingival plaque samples were analysed to seek for Porphyromonas gingivalis $(\mathrm{Pg})$ in both population in the case of periodontitis.

Results: The mean age of our patients was $40.75 \pm 12.04$, the mean duration of the illness was $14.30 \pm 6.76$ months (extremes: 1-24 months). ACPA was detected in $88 \%$ of patients and the mean titre was $255.57 \pm 409.78$. PD frequency was higher in patient with PR compared with healthy controls (43\% versus $29 \%$ ) and a significant association was found between PR and PD $(p<10-3)$. Patients with RA had $2.46(\mathrm{Cl} 1.12$ to 5.39$)$ higher odds of having PD compared with healthy controls. In early RA, ACPA titre and rate was not associated with PD $(p=0.06, p=0.44$ respectively). Regarding the frequency of Porphyromonas gingivalis, there was no significant difference between the PR group and the control group $(p=0.45)$. In addition, there was no significant difference between RA group and controls $(p=0.68)$ concerning Porphyromonas gingivalis and ACPA

Conclusions: Periodontitis is a risk factor for the occurrence of rheumatoid arthritis. The ACPA does not seem to be related to periodontitis. In addition there was no association between ACPA and the presence of porphyromonas gingivalis.

\section{REFERENCES:}

[1] Eriksson K, Nise L, Kats A, Luttropp E, Catrina Al, Askling J, Jansson L, Alfredsson L, Klareskog L, Lundberg K, Yucel-Lindberg T. Prevalence of Periodontitis in Patients with Established Rheumatoid Arthritis: A Swedish Population Based Case-Control Study. PLoS One 2016;11(5):e0155956.

[2] Laugisch O, Wong A, Sroka A, Kantyka T, Koziel J, Neuhaus K, Sculean A, Venables PJ, Potempa J, Möller B, Eick S. Citrullination in the periodontium -a possible link between periodontitis and rheumatoid arthritis. Clin Oral Investig 2016;20(4):675-683.

[3] Dissick A, Redman RS, Jones M, Rangan BV, Reimold A, Griffiths GR, et al. Association of Periodontitis with Rheumatoid Arthritis: A Pilot Study. Journal of Periodontology 2010;81:223-230.

[4] Mikuls TR, Payne JB, Yu F, et al. Periodontitis and porphyromonas gingivalis in patients with rheumatoid arthritis. Arthritis \& Rheumatology 2014;66(5):1090-100.

Disclosure of Interest: None declared

DOI: 10.1136/annrheumdis-2018-eular.5346

\section{FRI0017 AN EXPLORATORY STUDY ON THE ROLE OF VITAMIN D SUPPLEMENTATION IN IMPROVING PAIN AND DISEASE ACTIVITY IN RHEUMATOID ARTHRITIS}

G. Adami ${ }^{1}$, O. Viapiana ${ }^{1}$, L. Bogliolo ${ }^{2}$, F.P. Cantatore $^{3}$, M. Varenna ${ }^{4}$, N. Malavolta ${ }^{5}$, A. Del Puente ${ }^{6}$, M. Muratore ${ }^{7}$, G. Orsolini ${ }^{1}$, D. Gatti ${ }^{1}$, M. Rossini ${ }^{1}$, on behalf of Study Group on Osteoporosis and Metabolic Skeletal Diseases of the Italian Society of Rheumatology (SIR). ${ }^{1}$ Rheumatology Unit, University of Verona, Verona; ${ }^{2}$ Rheumatology Unit, Policlinico San Matteo Foundation/University of Pavia, Pavia; ${ }^{3}$ Rheumatology Unit, University of Foggia, Foggia; ${ }^{4}$ Rheumatology Unit, Gaetano Pini Institute, Milano; ${ }^{5}$ Rheumatology Unit, University of Bologna Sant'OrsolaMalpighi Hospital, Bologna; ${ }^{6}$ Rheumatology Unit, University Federico II of Naples, Napoli; ${ }^{7}$ Rheumatology Unit, Galateo San Cesario Hospital, Lecce, Italy

Background: Lower serum vitamin D levels have been associated with various autoimmune disorders. Especially in patients affected by Rheumatoid Arthritis
(RA), has been observed an inverse correlation between serum levels of 25hydroxyvitamin D (25OHD), pain and disease activity, but the cause-effect relationship is not clear

Objectives: The aim of this exploratory study is to investigate the effects of supplementation with cholecalciferol (vitD3) in improving pain and disease activity in RA patients with or without vitamin D deficiency $(250 \mathrm{HD}<20 \mathrm{ng} / \mathrm{ml})$.

Methods: In this prospective open-label intervention study, patients fulfilling the EULAR/ACR 2010 criteria for diagnosis of RA, in non-remission (DAS28$\mathrm{CRP}>2,6$ ), on stable disease-modifying antirheumatic drugs, and whose treatment was not expected to be changed over a 3 month period following inclusion, were recruited. DAS28-CRP, VAS pain and serum levels of $250 \mathrm{HD}$, were evaluated at the baseline and after 3 months of supplementation with oral 100,000 IU/ monthly of vitD3.

Results: A sample composed by 61 patients (47 females), with an average age (SD) of 5812 years within $26-86$ years range were included. At baseline the mean (SD) $25 \mathrm{OHD}$ levels were $2210 \mathrm{ng} / \mathrm{mL}$. $57 \%$ of the patients were found to have vitamin D deficiency $(<20 \mathrm{ng} / \mathrm{mL}$ ). Mean serum $250 \mathrm{HD}$ levels improved from $13 \pm 5$ to $32 \pm 12$ and from $29 \pm 7$ to $41 \pm 10 \mathrm{ng} / \mathrm{mL}$ in patients with or without vitamin $D$ deficiency, respectively. At baseline, mean VAS pain was significantly higher in patients with vitamin D deficiency. In the figure are shown DAS28-CRP and VAS pain at baseline and after 3 months of vitD3 supplementation both in patients with or without vitamin D deficiency. After large doses of VitD3, VAS pain significantly decreased in patients with vitamin D deficiency, while DAS28-CRP significantly improved only in patients without vitamin $D$ deficiency at baseline.

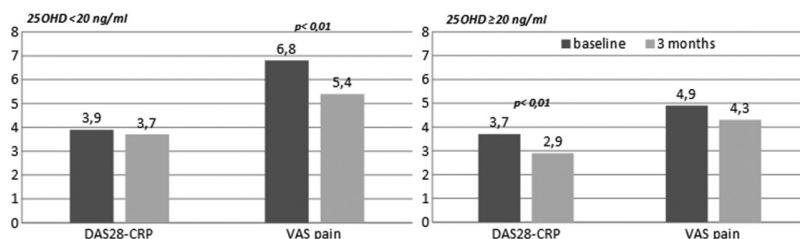

Conclusions: VitD3 supplementation appears to be associated with significant and different effects on pain and disease activity in RA patients dependent on $250 H D$ serum levels. Vitamin D deficiency $(<20 \mathrm{ng} / \mathrm{mL})$ seems to be mainly correlated with pain, while higher levels of $25 \mathrm{OHD}$ might have immunomodulatory effects. A randomised, double-blind, low versus high vitD3 dose, placebo-controlled trial is recommended.

Disclosure of Interest: None declared

DOI: 10.1136/annrheumdis-2018-eular.5235

\section{FRI0018 THE ABILITY OF DISEASE ACTIVITY MEASURES TO PREDICT MAJOR THERAPEUTIC CHANGE IN US VETERANS WITH RHEUMATOID ARTHRITIS}

G. Cannon ${ }^{1}$, C.-C. Teng ${ }^{1}$, N.A. Accortt ${ }^{2}$, D.H. Collier ${ }^{2}$, T.-C. Lin ${ }^{2}$, B.C. Sauer ${ }^{1} .{ }^{1}$ Salt Lake City VA Medical Center and University of Utah, Salt Lake City; ${ }^{2}$ Amgen, Thousand Oaks, USA

Background: Current rheumatoid arthritis (RA) treatment guidelines recommend the use of disease activity measures (DAMs) to guide RA therapy. These guide lines recommend considering escalation of therapy in RA patients with high or moderate disease activity. Recent work by our group has demonstrated that many RA patients with high/moderate RA by Disease Activity Score with 28 joints (DAS28) did not have therapy escalated despite active disease (DAS28 $\geq 3.2$ ).

Objectives: 1) To determine if the rate of major therapeutic change (MTC) for RA patients with high/moderate disease activity based on DAS28 was similar when measured using two other common DAMs; 2) to compare the ability of different DAMs to predict MTC across the full spectrum of RA disease activity.

Methods: US Veterans enrolled in the VA Rheumatoid Arthritis (VARA) registry with 1) a complete set of DAMs (DAS28, Clinical Disease Activity Index [CDAI], Routine Assessment of Patient Index Data 3 [RAPID3]) recorded (index date), 2) two other visits during the preceding 18 months separated by at least 60 days, and 3) clinical data available for 18 months prior to through 30 days following index date were eligible. Each patient was assessed for MTC within 1 week before and 30 days after index date. MTC was defined as any of the following: 1) initiation of new biologic or nonbiologic DMARD, 2) escalation of DMARD dose by $\geq 25 \%$, 3) initiation of prednisone (as new agent or after 90 day gap during baseline), or 4) increase in monthly average prednisone dose by $25 \%$ and/or 5 ) injection of 2 or more joints with corticosteroids. MTC was analysed by DAM severity thresholds of 1) high, moderate, low, and remission, and 2) high, high/moderate, and high/moderate/low levels. Analyses of the latter thresholds included sensitivity, specificity, predictive values, and accuracy estimations for MTC at each DAM level.

Results: Of 1776 eligible patients, $89 \%$ were male, mean age was 63.4 years, mean disease duration was 13.4 years, $79 \%$ tested positive for rheumatoid factor, 
and $63 \%$ positive for anti-cyclic citrullinated peptide antibodies. Overall, $33.1 \%$ $(591 / 1776)$ of patients had an MTC. A markedly larger percentage of patients with high disease activity had MTC (range 55.1\%-43.5\%) compared to patients with moderate disease (range 38.7\%-27.8\%) (table 1). Sensitivity, specificity, predictive values, and accuracy at each DAM threshold level varied markedly by DAM, with RAPID3 having a higher sensitivity, lower specificity, and less accuracy than DAS28 or CDAI (table 2).

Abstract FRI0018 - Table 1. Rates of MTC Stratified by DAM

\begin{tabular}{|lccc|}
\hline & \multicolumn{3}{c|}{ Patients with MTC, n/N (\%) } \\
\cline { 2 - 4 } High & DAS28 & CDAl & RAPID3 \\
Moderate & $285 / 737(38.7 \%)$ & $219 / 601(36.4 \%)$ & $155 / 558(27.8 \%)$ \\
Low & $72 / 283(25.4 \%)$ & $105 / 547(19.2 \%)$ & $47 / 217(21.7 \%)$ \\
Remission & $69 / 443(15.6 \%)$ & $36 / 209(17.2 \%)$ & $43 / 206(20.9 \%)$ \\
n, number of patients with MTC; $N$, number of patients with level of disease severity.
\end{tabular}

Abstract FRI0018 - Table 2. Performance of DAMs for Prediction of MTC

\begin{tabular}{|c|c|c|c|c|}
\hline & & & itive Thres! & \\
\hline & & High & $\begin{array}{c}\text { High/ } \\
\text { Moderate }\end{array}$ & $\begin{array}{c}\text { High/ } \\
\text { Moderate/ } \\
\text { Low }\end{array}$ \\
\hline Sensitivity & $\begin{array}{l}\text { DAS28 } \\
\text { CDAl } \\
\text { RAPID3 }\end{array}$ & $\begin{array}{l}27.9 \% \\
39.1 \% \\
58.5 \%\end{array}$ & $\begin{array}{l}76.1 \% \\
76.1 \% \\
84.8 \%\end{array}$ & $\begin{array}{l}88.3 \% \\
94.9 \% \\
92.7 \%\end{array}$ \\
\hline Specificity & $\begin{array}{l}\text { DAS28 } \\
\text { CDAI } \\
\text { RAPID3 }\end{array}$ & $\begin{array}{l}87.5 \% \\
84.1 \% \\
62.1 \%\end{array}$ & $\begin{array}{l}49.4 \% \\
51.9 \% \\
28.1 \%\end{array}$ & $\begin{array}{l}31.6 \% \\
14.6 \% \\
13.8 \%\end{array}$ \\
\hline $\begin{array}{l}\text { Positive } \\
\text { Predictive } \\
\text { Value }\end{array}$ & $\begin{array}{l}\text { DAS28 } \\
\text { CDAl } \\
\text { RAPID3 }\end{array}$ & $\begin{array}{l}52.7 \% \\
55.1 \% \\
43.5 \%\end{array}$ & $\begin{array}{l}42.9 \% \\
44.1 \% \\
37.0 \%\end{array}$ & $\begin{array}{l}39.2 \% \\
35.4 \% \\
34.9 \%\end{array}$ \\
\hline $\begin{array}{l}\text { Negative } \\
\text { Predictive } \\
\text { Value }\end{array}$ & $\begin{array}{l}\text { DAS28 } \\
\text { CDAl } \\
\text { RAPID3 }\end{array}$ & $\begin{array}{l}70.9 \% \\
73.5 \% \\
75.0 \%\end{array}$ & $\begin{array}{l}80.6 \% \\
81.3 \% \\
78.7 \%\end{array}$ & $\begin{array}{l}84.4 \% \\
82.8 \% \\
79.1 \%\end{array}$ \\
\hline Accuracy & $\begin{array}{l}\text { DAS28 } \\
\text { CDAl } \\
\text { RAPID3 }\end{array}$ & $\begin{array}{l}67.7 \% \\
69.1 \% \\
60.9 \%\end{array}$ & $\begin{array}{l}58.3 \% \\
60.0 \% \\
47.0 \%\end{array}$ & $\begin{array}{l}50.5 \% \\
41.0 \% \\
40.0 \%\end{array}$ \\
\hline
\end{tabular}

Conclusions: Most patients with high/moderate disease activity did not have a MTC. This observation was consistent regardless of which DAM was utilised. MTC increased with disease activity with all DAMs; however, DAS28 and CDAI appeared to have greater accuracy than RAPID3 at predicting MTC at all disease severity thresholds. There is need for continued evaluation of DAM thresholds for defining disease activity for MTC decisions, better DAMs, and/or better application of DAMs in clinical practice to improve the treatment of patients with active RA.

Acknowledgements: This study was sponsored by Immunex, a subsidiary of Amgen. Medical writing assistance provided by Amgen.

Disclosure of Interest: G. Cannon Grant/research support from: Amgen, C.-C. Teng Grant/research support from: Amgen, N. Accortt Shareholder of: Amgen, Employee of: Amgen, D. Collier Shareholder of: Amgen, Employee of: Amgen, T.C. Lin Shareholder of: Amgen, Employee of: Amgen, B. Sauer Grant/research support from: Amgen Inc.

DOI: 10.1136/annrheumdis-2018-eular.1804

\section{FRI0019 ARE DISEASE ACTIVITY, DISABILITY OR PSYCHOLOGICAL FACTORS MOST ASSOCIATED WITH PATIENTS WITH RHEUMATOID ARTHRITIS BEING SATISFIED WITH THEIR CONDITION AFTER 12 MONTHS FOLLOWING TREATMENT ONSET?}

J. Gwinnutt ${ }^{1}$, K. Hyrich ${ }^{1,2}$, M. Lunt ${ }^{1}$, A. Barton ${ }^{2,3}$, S. Verstappen ${ }^{1,2}$, on behalf of RAMS coinvestigators. ${ }^{1}$ Arthritis Research UK Centre for Epidemiology, The University of Manchester, ${ }^{2}$ NIHR Manchester Biomedical Research Centre, Manchester University Hospitals NHS Foundation Trust: ${ }^{3}$ Arthritis Research UK Centre for Genetics and Genomics, The University of Manchester, Manchester, UK

Background: An important treatment goal in the management of patients with rheumatoid arthritis (RA) is patients being satisfied with their condition, the patient acceptable symptom state (PASS). It is unclear whether reduction in disease activity, the main therapeutic aim of RA treatment, is associated with reaching PASS, or whether reductions in other factors are also important.
Objectives: To analyse change over one year of disease activity, patient reported outcomes (PROs) and psychological factors and their association with PASS at one year.

Methods: The Rheumatoid Arthritis Medication Study (RAMS) is a prospective cohort of patients with RA starting MTX for the first time in the United Kingdom. At baseline and one year, patients reported demographics and completed pain and fatigue visual analogue scales (VAS-pain/VAS-fatigue), the Hospital Anxiety and Depression Scale (HADS-A, HADS-D) and the Health Assessment Questionnaire (HAQ). A research nurse performed a 28 swollen and tender joint count (SJC28/ TJC28) and the disease activity score (DAS28) was calculated. Patients answered the question "Is your current condition satisfactory, when you take your general functioning and your current pain into consideration?" at baseline and a one year. Only patients not in PASS at baseline are included in this analysis. Change in disease related factors (SJC28, TJC28, DAS28), PROs (HAQ, VASpain, VAS-fatigue), and psychological factors (HADS-A, HADS-D) from baseline to one year were calculated (see table 1). Predictors of PASS at one year were assessed using multivariable logistic regression, adjusting for age and gender The discriminative power of disease activity, PROs and psychological factors were assessed by comparing the area under the curve (AUC) of the receiver operating characteristic curve.

Results: Of 358 not in PASS at baseline (mean (SD) age: 58.1 (13.0) years; 244 (68.2\%) women), 241 (67.3\%) were in PASS after one year. The only independent predictors of PASS were change in HAQ, VAS-pain and HADS-D (OR $(95 \% \mathrm{Cl})$ per unit change from baseline: HAQ $0.38(0.16,0.91)$; VAS-pain $0.96(0.95,0.98)$; HADS-D $0.86(0.75,0.99))$. The model containing PROs had significantly greate AUC compared to a disease activity model $(0.91$ vs. $0.84, p=0.004)$ and a psychological factors model (0.91 vs. $0.81, \mathrm{p}<0.0001)$

Abstract FRI0019 - Table 1. Baseline, one year and change scores stratified by whether patients were in PASS at one year

\begin{tabular}{|c|c|c|c|c|c|c|}
\hline \multirow{2}{*}{ Variable } & \multicolumn{2}{|c|}{ Median (IQR) baseline score } & \multicolumn{2}{|c|}{ Median (IQR) one year score } & \multirow{2}{*}{\multicolumn{2}{|c|}{$\begin{array}{c}\text { Median (IQR) Change } \\
\text { PASS at one Not-PASS at one }\end{array}$}} \\
\hline & PASS at one & Not-PASS at one & PASS at one & Not-PASS at one & & \\
\hline Disease activity & & & & & & \\
\hline & $6.5(2.5,11.0)$ & $6.0(3.0,12.0)$ & $0.0(0.0,2.0)$ & $3.0(0.0,7.0) \ddagger$ & $-5(-9,-2)$ & $-2(-6,1) \neq$ \\
\hline TJC28 & $6.0(3.0,12.0)$ & $9.0(5.0,17.0)^{+}$ & $1.0(0.0,4.0)$ & $8.0(2.0,14.0) \neq$ & $-4(-9,-1)$ & \\
\hline DAS28 & $4.6(3.8,5.4)$ & $4.9(4.2,5.8)$ & $2.7(2.1,3.5)$ & $4.3(3.5,5.3) \neq$ & $-1.6(-2.9,-0.8)$ & $-0.6(-1.6,0.4)$ \\
\hline$H A Q$ & $1.3(0.8,1.8)$ & $1.4(1.0,1.9)$ & $0.6(0.1,1.1)$ & $1.5(1.0,1.9) \neq$ & $-0.5(-1.0,-0.1)$ & $0.0(-0.4,0.3) \neq$ \\
\hline VAS-Pain & $63(46,75)$ & $68(50,80)$ & $18(7,33)$ & $60(41,76) \neq$ & $-38(-55,-18)$ & $-5(-24,9) \neq$ \\
\hline $\begin{array}{l}\text { VAS-Fatigue } \\
\text { psychol }\end{array}$ & $62(37,74)$ & $72(57,85) \neq$ & $29(13,54)$ & $70(55,83) \div$ & $-24(-43,-1)$ & $-1(-17,12) \neq$ \\
\hline $\begin{array}{l}\text { Psychological } \\
\text { HADS-D }\end{array}$ & $7(4,10)$ & $8(5,10)$ & $3(1.6)$ & $8(5,11) \neq$ & $-2(-5,0)$ & $1(-1,2) \neq$ \\
\hline HADS-A & $6(4,10)$ & $8(4,12) \pm$ & $4(2,8)$ & $8(4,11) \neq$ & $-2(-4,0)$ & $0(-2,2) \neq$ \\
\hline
\end{tabular}

Conclusions: Change in PROs have a greater association with attaining PASS at one year compared to disease related or psychological factors and should be taken into account when designing treatment strategies.

Disclosure of Interest: None declared

DOI: 10.1136/annrheumdis-2018-eular.5212

\section{FRI0020 ANTI-CEP-1 ANTIBODIES AND OTHER AUTOANTIBODIES IN EARLY ARTHRITIS}

M. Ponikowska ${ }^{1}$, J. Świerkot ${ }^{2}$, B. Nowak ${ }^{3}$, L. Korman ${ }^{2}$, P. Wiland ${ }^{2}{ }^{1}$ Department of Rheumatology and Internal Medicine, Wroclaw University Hospital; ${ }^{2}$ Department of Rheumatology and Internal Medicine; ${ }^{3}$ Department of Pharmacology, Wroclaw Medical University, Wroclaw, Poland

Background: As it is very important to identify patients with a high risk of developing rheumatoid arthritis (RA), new, diagnostic methods, evaluating the possibility of progression from undifferentiated arthritis (UA) to RA are needed.

Objectives: The aim of this work was the evaluation of the frequency of rheumatoid factor, anti-cyclic citrullinated peptide (anti-CCP) antibodies, mutated citrullinated vimentin antibodies (a-Sa), anti-CEP-1 antibodies, anti-filaggrin antibodies (AFA), heterogeneous nuclear ribonucleoprotein compies/anti-RA33-antibody (HnRNP/RA33), anti-CarP antibodies (a-Carp) in patients with early arthritis.

Methods: 74 patients with early arthritis and 20 healthy volunteers were enrolled to the study. 51 patients were diagnosed with RA, 23 with UA. Exclusion criteria were the application of disease-modifying antirheumatic drugs or glucocorticosteroids. In all patients the following laboratory tests were performed: inflammatory markers, rheumatoid factor (RF) and antibodies mentioned above, together with necessary diagnostic that enables diagnosis.

Results: In patients with early arthritis the sensitivity and specificity of the presence of RF was $69 \%$ and $95 \%$, respectively, and of anti-CCP was $67 \%$ and $97 \%$.

In patients with early arthritis we observed significantly higher concentration of CEP-1 $(65,8 \pm 111,6)$ than in the healthy group $(2,0 \pm 0,0)$. In $R F(+) R A$ patients we 